\title{
Electric vehicle driving range extension using photovoltaic panels
}

\author{
Stefano De Pinto, Qian Lu, Pablo Camocardi, Christoforos Chatzikomis, Aldo \\ Sorniotti ${ }^{1}$, Constantina Lekakou \\ University of Surrey \\ Guildford, United Kingdom \\ ${ }^{1}$ Corresponding author, Email: a.sorniotti@surrey.ac.uk
}

\author{
Domenico Ragonese \\ STMicroelectronics \\ Catania, Italy
}

\author{
Gregorio Iuzzolino, Pietro Perlo \\ Interactive Fully Electric Vehicles (IFEVS) \\ Torino, Italy
}

\begin{abstract}
This paper investigates the potential benefits of photovoltaic (PV) panels on electric vehicles. In addition to the PV panels on the roof of the car, in this study a PV panel is installed below the windshield to increase energy capture when the car is parked. An electro-mechanical actuator makes the PV panel disappear under the roof when the passengers are in the vehicle. The paper presents the simulation model of the overall $P V$ architecture, including the DC/DC converter and the energy storage system. Based on recorded temperature and solar irradiance profiles, the model calculates the energy input and the corresponding range extension. The resulting values are discussed for a prototype four-wheel-drive urban electric vehicle operating in five European locations.
\end{abstract}

Keywords - PV panels, electric vehicles, windshield, range extension.

\section{LIST OF SYMBOLS}

$A_{1}, A_{2}$ : constants of the PV panel model

$C$ : capacitance

$E$ : equilibrium potential

$G$ : solar irradiance

$I$ : current

$P$ : power

$Q$ : capacity of the battery pack

$R$ : resistance

SOC: state-of-charge

$t$ : time

$T:$ temperature

$V$ : voltage

$\alpha$ : current temperature coefficient

$\beta$ : voltage temperature coefficient

$\gamma$ : battery temperature factor

$\eta$ : efficiency

$\mu$ : battery rate factor

The following subscripts are used in the paper:

Batt: battery

$M P P$ : maximum power point

$M P P T$ : maximum power point tracking

$M P P S$ : maximum power point at standard conditions

$O C$ : open circuit

$O C S$ : open circuit at standard conditions

$P$ : panel

$S:$ standard conditions

$S C$ : short circuit

$S C S$ : short circuit at standard conditions

sim: simulation
0 : initial value

\section{INTRODUCTION}

Due to the uncertainty of the global energy scenarios and severity of the environmental pollution, solar energy has become a widely used renewable energy source for various applications. In recent years, several studies dealt with the integration of photovoltaic (PV) panels into electric vehicles (EVs) and hybrid electric vehicles (HEVs). These integration efforts can bring benefits, such as reduction in energy consumption and emissions, and decrease in battery recharge time. Automotive PV systems will also facilitate the adoption of vehicle-to-grid (V2G) technologies.

An overview of the automotive applications of solar energy is provided in [1]. The first combinations of solar energy and EVs date back to the late 1970s and early 1980s [2]. For example, a solar car prototype was proposed by James Worden in 1984 . These early amateurish prototypes were not intended for use in daily transportation, but rather as demonstration vehicles to generate research and public interest in solar energy for automotive applications. One of the most famous solar race vehicles is Nuna 3, developed by Delft University and winner of the World Solar Challenge in 2005. Nuna 3 was powered solely by solar energy, and achieved $\sim 100 \mathrm{~km} / \mathrm{h}$ of average speed during the competition.

In the area of HEVs, an innovative vehicle, Viking 23, was developed at Western Washington University, integrating PV panels into a parallel HEV architecture [3]. A prototype of solar hybrid electric car was tested by Sasaki et al. in 1997 [4], while a series HEV prototype was co-developed by the University of Salerno [5-6]. The studies of Arsie et al. [5-6], referred to the latter vehicle, show an overall $30 \%$ fuel saving, achieved through the combination of high-efficiency solar panels, battery optimization, and vehicle weight reduction.

Also in EVs and HEVs developed by major car makers, PV panels have been used as additional power sources aiming at reducing energy consumption, by charging the traction battery and/or alleviating the load related to the vehicle ancillary systems. For example, in 2008 FIAT presented the prototype city car Phylla, with a $1 \mathrm{~kW}$ hydrogen fuel cell, including PV panels on the roof and doors. Toyota has recently implemented a version of the Prius with a PV panel on the roof. The aim is to support the air conditioning system and other accessories when the vehicle is driven, and recharge the battery when the vehicle is parked. This set-up achieves a $10 \%$ saving in fuel consumption with respect to the original HEV [7]. In 2014 Ford presented the C-Max Solar Energy 
Concept, its first HEV with a PV system. For that application, researchers developed an off-vehicle solar concentrator with a special lens to direct sunlight to the PV panels, thus boosting the impact of the PV system by a factor of eight.

In general, the main limitations to the automotive application of PV technologies are the low energy density, the significant packaging constraints of conventional cars, and cost To maximize the solar energy contribution, it is sensible to make extended usage of the car body surface, rather than limiting the PV installation to the roof. For this reason, windows were covered with transparent panels by Saitoh et al. [8], and the doors were used for PV installation on the Phylla. A moving solar roof with self-orienting capability was proposed by Coraggio et al. [9] to extract maximum power. However, these applications pose issues in terms of visibility, aesthetics and functionality.

To the best knowledge of the authors, the literature presents a significant gap in the detailed quantitative assessment of the EV range extension achievable through the integration of PV panels. In this respect, the objectives of this study are:

- The description of a PV panel area extension system, based on an additional movable PV panel located behind the windshield.

- The implementation of a realistic simulation model of a case study urban EV with PV panels.

- The evaluation of the PV-related driving range extension for a variety of operating conditions, locations and solar irradiance levels.

The paper is structured as follows. Section II provides a brief description of the proposed PV-based battery charging system, and the sliding mechanism for the PV panel behind the windshield. Section III presents the simulation model of the overall PV system, which is validated against experimental results in Section IV. Section V discusses the simulation-based driving range extension results, while conclusions are given in Section VI.

\section{ELECTRIC VEHICLE WITH THE PV-BASED BATTERY CHARGING SYSTEM}

This study is based on the urban four-wheel-drive electric vehicle (4WD EV) prototype developed within the FP7 European Union-funded projects FREE-MOBY [10] and PLUS-MOBY [11]. Figures 1a) and 1b) show the physical implementations of the vehicle, which can be used for passenger transportation or as a mobile food van. Figure 1c) is the simplified schematic of the drivetrain layout. Each onboard drivetrain consists of an induction electric motor drive, which transmits torque to the wheels through a two-speed gearbox, an open differential, constant-velocity joints and half-shafts.

The 4WD EV in the configuration of Figure 1a) is characterized by three solar panels on the roof, with a total area of $\sim 1.1 \mathrm{~m}^{2}$ (this area is larger for the configuration in Figure 1b)). In order to increase the energy capture, an additional PV panel is installed behind the windshield, with an area of $\sim 0.4 \mathrm{~m}^{2}$. This PV panel is activated only when the vehicle is parked. In this condition the panel slides down behind the windshield through an electro-mechanical actuator, while it slides back under the roof when the car is driven. Figure 2 shows the prototype of the system concept, implemented in the IFEVS laboratory.

The electric architecture of the PV-based battery charging system is described in Figure 3. The four PV panels are connected in parallel, sharing the same voltage. Each of the four PV panels of the prototype implementation consists of 24 C60 crystalline silicon solar cells [12] in series, arranged in two PV strings, including 12 PV cells each, as shown in Figure. Each panel can supply $\sim 80 \mathrm{~W}$ in peak power conditions. A drawback of the series connection of PV cells is that the performance of the whole panel is affected, if a single cell is shaded. This effect can be mitigated through the adoption of bypass elements. In the specific prototype the PV panels integrate two smart bypass elements, connected in parallel to the two PV strings, thus providing an alternative path for the current.

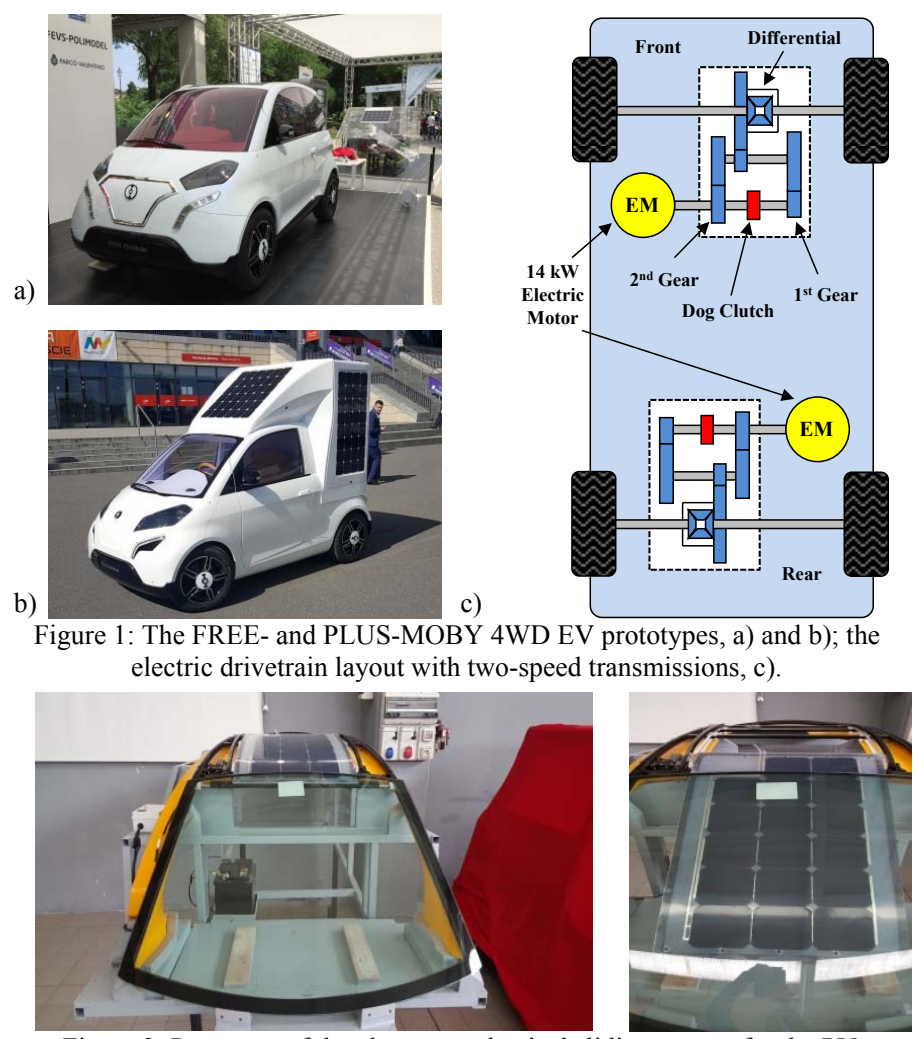

Figure 2: Prototype of the electro-mechanical sliding system for the PV panel located behind the windshield when the EV is parked.

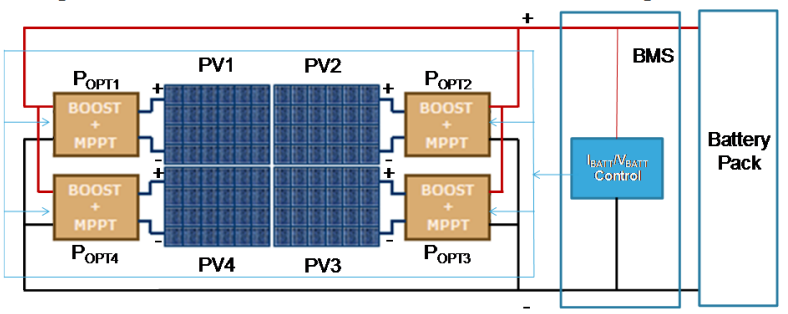

Figure 3: Simplified schematic of the electric architecture of PV-based battery charging system. 


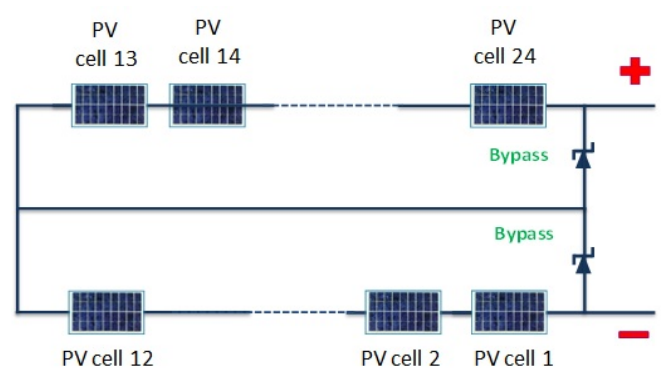

Figure 4: Layout of the individual PV panels including bypass elements.

The PV panels charge the traction battery pack through flyback DC/DC converters, boosting the voltage and providing electrical insulation. Given the intrinsically low power density of the system, the power converter must be able to regulate the PV terminal voltage to extract the maximum possible power in any condition. For this reason, a power optimizer integrated with a maximum power point tracking (MPPT) algorithm $[13,14]$ controls the DC/DC converters according to the actual solar irradiance level. The output voltage of the $\mathrm{DC} / \mathrm{DC}$ converters is regulated based on a constant current/constant voltage $(\mathrm{CC} / \mathrm{CV})$ control mechanism to match with the battery voltage. The $\mathrm{CC} / \mathrm{CV}$ controller and power optimizer are connected by an opto-coupler for insulation-related reasons. The optimizers are implemented through the integrated circuit SPV1020 (commercial product by STMicroelectronics).

The EV battery pack consists of four modules, each of them characterized by a total number of 14 EIG lithium-ion polymer battery cells ( 2 branches in parallel with 7 cells in series each). The voltage level of the battery pack of the case study EV ranges from $\sim 90 \mathrm{~V}$ (battery discharged) to $\sim 115 \mathrm{~V}$ (battery fully charged). Independently from the PV-based system, the battery pack of the 4WD EV demonstrator can be charged by the electric grid through a CHAdeMO interface, and is swappable as well.

\section{SiMULATION MODELS}

The simulation models of the vehicle and PV-based battery charging system are implemented in Matlab/Simulink. In particular, the PV system model consists of three main blocks: A. the PV panel model; B. the DC/DC converter model; and C. the lithium-ion traction battery model. The model is used to predict the energy that the system can deliver to the EV battery, based on the solar irradiance level and PV panel temperature. The weather condition-related inputs used for the simulations are available from the European Commission's Joint Research Centre (JRC) website [15]. The PV system model mainly requires the parameters included in typical manufacturers' datasheets of the system components. In parallel with the PV system model, a high-fidelity vehicle model is used for assessing the EV energy consumption (see Section III.D).

\section{A. Solar panel model}

The adopted PV model is from Bellini et al. [16]. The model equations are:

$$
I_{P}=I_{S C}\left[1-A_{1}\left(e^{\frac{V_{P}}{A_{2} V_{O C}}}-1\right)\right]
$$

$$
\begin{gathered}
A_{1}=\left(1-\frac{I_{M P P}}{I_{S C}}\right) e^{-\frac{V_{M P P}}{A_{2} V_{O C}}} \\
A_{2}=\frac{\frac{V_{M P P}}{V_{O C}}-1}{\ln \left(1-\frac{I_{M P P}}{I_{S C}}\right)} \\
I_{S C}(G, T)=I_{S C S} \frac{G}{G_{S}}\left[1+\frac{\alpha}{100}\left(T-T_{S}\right)\right] \\
V_{O C}(T)=V_{O C S}+\beta\left(T-T_{S}\right) \\
I_{M P P}(G, T)=I_{M P P S} \frac{G}{G_{S}}\left[1+\frac{\alpha}{100}\left(T-T_{S}\right)\right] \\
V_{M P P}(T)=V_{M P P S}+\beta\left(T-T_{S}\right)
\end{gathered}
$$

where the standard conditions correspond to an irradiance level $G_{S}=1000 \mathrm{~W} / \mathrm{m}^{2}$ and a temperature $T_{S}=25^{\circ} \mathrm{C}$. Through Eq. (1) and its coefficients, obtained in Eqns. (2-7), the model allows to calculate the panel current, $I_{P}$, as a function of the panel voltage, $V_{P}$, for different temperatures, $T$, and solar irradiance levels, $G$. $G$ has a direct effect on the current, while its effect on the voltage can be compensated by controlling the $\mathrm{DC} / \mathrm{DC}$ converter. The maximum power is achieved by controlling the voltage at the optimal level, $V_{M P P}$, with the MPPT controller $[13,14]$. The main parameters of the selected solar panels are reported in Table I.

TABLE I: CASE STUDY PV PANEL PARAMETERS IN STANDARD CONDITIONS.

\begin{tabular}{ccc}
\hline \hline Parameter & Unit & Value \\
\hline$I_{S C S}$ & {$[\mathrm{~A}]$} & 6.28 \\
$V_{O C S}$ & {$[\mathrm{~V}]$} & 16.32 \\
$V_{M P P S}$ & {$[\mathrm{~V}]$} & 13.8 \\
$I_{M P P S}$ & {$[\mathrm{~A}]$} & 5.92 \\
$\alpha$ & {$\left[\% /{ }^{\circ} \mathrm{C}\right]$} & 0.032 \\
$\beta$ & {$\left[\mathrm{mV} /{ }^{\circ} \mathrm{C}\right]$} & -47.52 \\
\hline \hline
\end{tabular}

\section{B. DC/DC converter model}

As the DC/DC converter dynamics are much faster than those of the PV panels and lithium-ion batteries, the modeling of the transient response of the DC/DC converter can be neglected. As a consequence, the model is simplified into an efficiency map as a function of the input power and irradiance level, according to experimental results such as those in Figure 5, measured in the STMicroelectronics laboratory. The measurements show maximum efficiency values of $\sim 90 \%$.

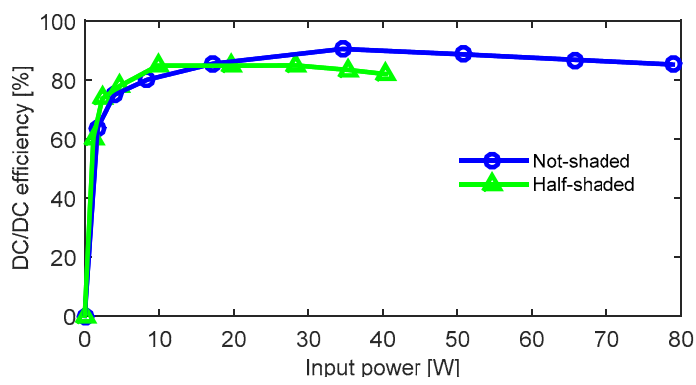

Figure 5: Example of experimentally measured efficiency maps of the DC/DC converter.

\section{Lithium-ion battery model}

The battery model from [17] is used, as it has already been validated for several commercial lithium-ion cells (e.g., Sony 
US 18650 and Panasonic CG18650), and because of its low computational requirements. The model is described by the equivalent electric circuit in Figure 6, consisting of: i) an equilibrium potential, $E_{B a t t}$, function of the state-of-charge, $S O C_{\text {Batt }}$, and temperature; ii) two resistors, $R_{1}$ and $R_{2}$, for computing the battery power losses; and iii) a capacitance, $C_{B a t t}$, which characterizes the transient response. $S O C_{B a t t}$ is defined as:

$$
\begin{gathered}
S O C_{\text {Batt }}=\frac{1}{Q_{\text {Batt }}} \int_{0}^{t_{\text {sim }}} \mu\left(I_{\text {Batt }}\right) \gamma\left(T_{\text {Batt }}\right) I_{\text {Batt }}(t) d t \\
+S O C_{\text {Batt }_{0}}
\end{gathered}
$$

The factors $\mu$ and $\gamma$ are included to take the effects of discharge rate and temperature into account. The main battery cell parameters are given in Table II.

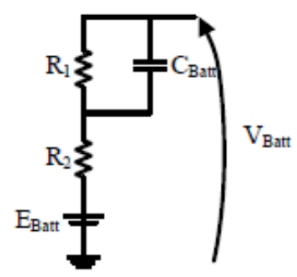

Figure 6: Equivalent electric circuit model of the lithium-ion battery.

TABLE II: MAIN CHARACTERISTICS OF THE LITHIUM-ION BATTERY CELLS.

\begin{tabular}{ccc}
\hline \hline Parameter & Unit & Value \\
\hline Nominal voltage & {$[\mathrm{V}]$} & 3.65 \\
Nominal capacity & {$[\mathrm{Ah}]$} & 20 \\
AC impedance (at $1 \mathrm{kHz})$ & {$[\mathrm{m} \Omega]$} & $<3$ \\
Specific energy & {$[\mathrm{Wh} / \mathrm{kg}]$} & 174 \\
Energy density & {$[\mathrm{Wh} / \mathrm{l}]$} & 370 \\
Specific power (at $\left.S O C_{\text {Batt }}=50 \%, 10 \mathrm{~s}\right)$ & {$[\mathrm{W} / \mathrm{kg}]$} & 2300 \\
\hline \hline
\end{tabular}

\section{Vehicle model}

A forward-facing simulation model of the longitudinal vehicle dynamics is implemented for the assessment of the energy consumption performance of the case study 4WD EV. The model includes the simulation of the drivetrain torsional dynamics, non-linear tire behavior (slip ratio dynamics) and gearshift dynamics [18,19]. The power losses related to aerodynamic drag, rolling resistance, longitudinal tire slip, electric motor drives and two-speed transmissions are individually accounted for.

\section{PV SYSTEM MODEL VALIDATION}

Figure 7 shows the static test rig used in IFEVS (in Rivoli, Italy) for validating the overall PV electric architecture. The test rig includes the same four panels that are installed on the car (Figure 7a)). The STMicroelectronics DC/DC converter is visible in Figures $7 \mathrm{~b}$ ) and $7 \mathrm{c}$ ), while the modules of the vehicle battery pack are in Figure 7d).

Experimental tests on the PV panels have been performed in multiple weather and temperature conditions. The measurements have been compared with the outputs from the PV panel simulation model in Section III.A (Figure 8). The model accurately fits with the measured PV curves, especially for solar irradiance values larger than $800 \mathrm{~W} / \mathrm{m}^{2}$.
The experimental validation of the overall PV system model has been carried out considering: i) solar irradiance sensor measurements along 24 hours, which are used as model inputs. The specific solar irradiance values are characterized by a sampling time of $~ 50$ minutes; and ii) the outputs from the battery management system (BMS), e.g., battery state-ofcharge and power (recorded with a sampling time of $10 \mathrm{~ms}$ ). The BMS data are compared with the PV system model results to assess model accuracy.

For example, Figures 9 and 10 show the comparison between the simulated and experimental time histories of battery power and state-of-charge during a test. In Figure 9 the lines 'test (non-filtered)' and 'test (filtered)' represent the experimental raw data and the experimental filtered data from the BMS, respectively. The lines 'simulation' in Figures 9 and 10 refer to the results of the PV system model, without considering the variation of panel efficiency as a function of panel temperature. The lines 'simulation with temperature effect' correspond to the simulation model outputs, with the efficiency of the solar panel expressed as a function of solar irradiance and panel temperature levels.

These results demonstrate that the PV panel temperature has a great impact on the performance of the overall PV system, especially when the temperature is high (e.g., between 11 am and $2 \mathrm{pm}$ in the specific test). This and other sets of experimentally validated simulations have proven the reliability of the model in predicting the battery energy input from the PV system.
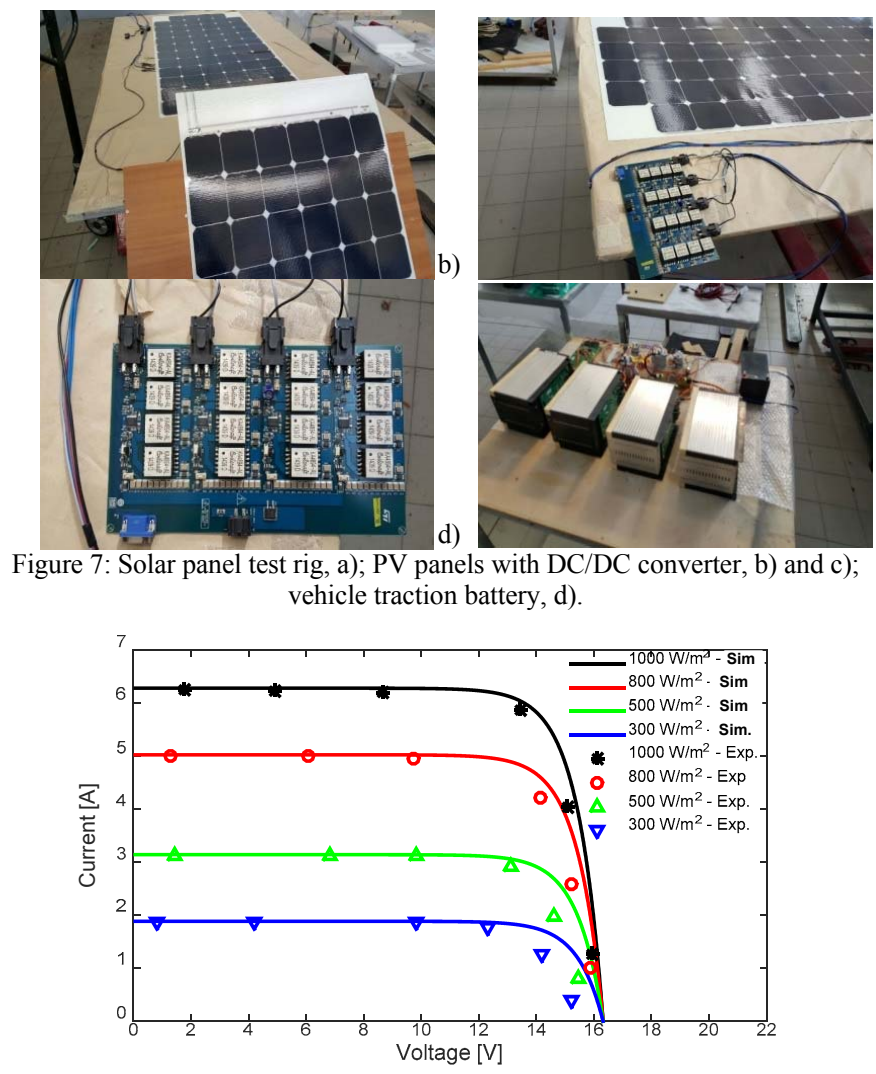

Figure 8: Experimental validation of the PV panel characteristics at different values of solar irradiance. 


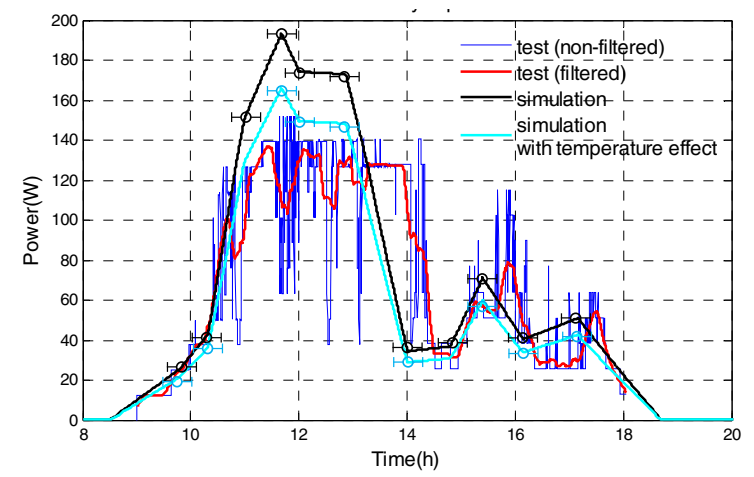

Figure 9: Experimental validation of the PV system: measured and simulated battery power profiles.

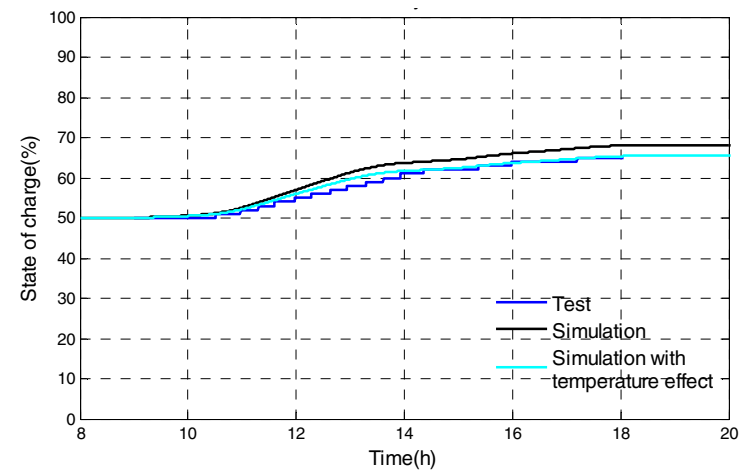

Figure 10: Experimental validation of the PV system: measured and simulated state-of-charge profiles of the battery.

\section{DRIVING RANGE EXTENSION USING PV ENERGY}

This section quantifies the range extension benefits that the PV system can bring to the case study EV.

Five European locations are selected, namely Berlin, Budapest, London, Stockholm and Turin. The solar energy captured and stored into the EV battery is predicted by using: i) the data of the respective solar irradiance profiles along arbitrary 24-hour-periods selected in different months of the year 2015 [15]; and ii) the PV system simulation model of Sections III and IV. The solar energy stored into the EV battery is estimated under the hypothesis that the vehicle remains parked in favorable position for the whole time relevant to energy capture, and hence with the windshield PV panel activated. A tilt angle of the windshield PV panel of 45 $\mathrm{deg}$ is considered in processing the irradiance profiles. Moreover, a corrective factor $(<1)$, experimentally tuned, simulates the filtering effect of the windshield.

The energy consumption values of the 4WD EV at different constant speeds $(30 \mathrm{~km} / \mathrm{h}, 50 \mathrm{~km} / \mathrm{h}$ and $70 \mathrm{~km} / \mathrm{h})$ and along the Urban Driving Cycle (UDC) are calculated under the hypothesis of a constant 50\% front-to-rear wheel torque distribution, with the simulation model of Section III.D (Table III). [20-23] are a small sample of the existing literature dealing with the analysis of EV energy consumption values and measurement procedures.

The range extension deriving from the PV panels, reported in Table IV, is obtained by combining the results in Table III with the daily PV-based battery energy input. For example, Table IV shows that the adoption of the PV system can extend the daily range by $\sim 8 \mathrm{~km}$ to $\sim 27 \mathrm{~km}$ with the UDC, depending on the season and location. However, these results are optimistic, e.g., because of the hypothesis of four panels always active for the PV-based battery recharging. Moreover, the realism of the values in Tables III and IV is affected by the significant uncertainty with respect to the actual vehicle operation, e.g., related to the lack of consideration of the power consumption from the ancillary systems installed on the EV. In fact, the energy consumption caused by the accessories, such as the heating and ventilation system, the various control units, the infotainment system and the lights can be important. As a consequence, the values in Table IV represent an indication of the maximum potential benefit in terms of range extension.

TABLE III: SIMULATED ENERGY CONSUMPTION VALUES OF THE PLUS-MOBY VEHICLE PROTOTYPE.

\begin{tabular}{lcccc}
\hline \hline & $30 \mathrm{~km} / \mathrm{h}$ & $50 \mathrm{~km} / \mathrm{h}$ & $70 \mathrm{~km} / \mathrm{h}$ & UDC \\
\hline Consumption $[\mathrm{Wh} / \mathrm{km}]$ & 38.80 & 53.03 & 74.64 & 56.94 \\
\hline \hline
\end{tabular}

TABLE IV: SIMULATED BATTERY ENERGY INPUTS FROM THE PV SYSTEM (ALONG ARBITRARY 24-HOUR PERIODS IN THE INDICATED MONTH) AND MAXIMUM VALUES OF THE RESPECTIVE DAILY RANGE EXTENSION.

\begin{tabular}{c|c|cccc}
\hline \hline \multicolumn{1}{c}{} & \multicolumn{5}{c}{ Maximum range extension [km] } \\
\hline $\begin{array}{c}\text { Month and European } \\
\text { Location }\end{array}$ & $\begin{array}{c}\text { Energy } \\
{[\mathrm{kWh}]}\end{array}$ & $\begin{array}{c}30 \\
\mathrm{~km} / \mathrm{h}\end{array}$ & $\begin{array}{c}50 \\
\mathrm{~km} / \mathrm{h}\end{array}$ & $\begin{array}{c}70 \\
\mathrm{~km} / \mathrm{h}\end{array}$ & $\mathrm{UDC}$ \\
\hline September - Berlin & 0.794 & 20.5 & 15.0 & 10.6 & 13.9 \\
February - Budapest & 0.426 & 11.0 & 8.0 & 5.7 & 7.5 \\
April - London & 1.106 & 28.5 & 20.9 & 14.8 & 19.4 \\
July - Stockholm & 1.324 & 34.1 & 25.0 & 17.7 & 23.3 \\
August - Turin & 1.488 & 39.9 & 29.2 & 20.7 & 27.2 \\
\hline \hline
\end{tabular}

Based on the previous discussion, for a specific location, Turin, more detailed estimates of the achievable range extension are produced, based on the average daily solar irradiance data of each month of 2015. The following scenarios are included:

- Scenario A, with the same approximations as in Tables III and IV, i.e., four panels always active and zero power consumption from the vehicle ancillary systems.

- Scenario B, with the same approximations as for Scenario A, apart from the exclusion of the windshield PV panel, i.e., only the three PV panels on the roof are used for charging the battery.

- Scenario C, with the same approximations as for Scenario A, apart from the consideration of the ancillary power losses, estimated starting from realistic data for the specific 4WD EV demonstrator. In particular, an average power consumption caused by the ancillaries of $1060 \mathrm{~W}$ is considered, which corresponds to an additional energy consumption of $157.8 \mathrm{Wh}$ along the $536 \mathrm{~s}$ of the UDC, and an additional consumption per unit distance of 39.7 $\mathrm{Wh} / \mathrm{km}$ for the same driving cycle. These values are considered conservative (i.e., they represent the worst case) for the specific 4WD EV.

- Scenario D, with only three active PV panels as in Scenario B, and considering the same power consumption of the ancillary systems as in Scenario C. 
The histograms in Figure 11 report the range extension results in $\mathrm{km}$ along the UDC, for Scenarios A-D. The power consumption associated with the ancillaries is always more influential than the range extension caused by the movable panel. The estimated average daily PV-based range extension is of $\sim 18.2 \mathrm{~km}$ according to Scenario A. The average daily range extension difference along the year between the best case, i.e., Scenario A, and the worst case, i.e., scenario D, is of $\sim 9.9 \mathrm{~km}$.

When considering that the maximum average daily distance traveled by the PLUS-MOBY vehicle is expected to be of $\sim 30 \mathrm{~km}$, the range extension benefit of the PV system remains very significant in all scenarios. On the other hand, the additional final cost for the customer related to the installation of the PV system is estimated to be in the region of $\sim 1500 €$ for the specific EV. When considering the electricity price per $\mathrm{kWh}$ in a charging station or household (for example, see the electricity tariffs in [24]) and that the maximum yearly PV system battery energy input in Turin is of $\sim 380 \mathrm{kWh}$, the customer is unlikely to experience a financial benefit, even after several years of vehicle usage. The additional investment at the vehicle purchase is justifiable only if the customer appreciates the range extension and increased flexibility brought by the PV system as an added value.

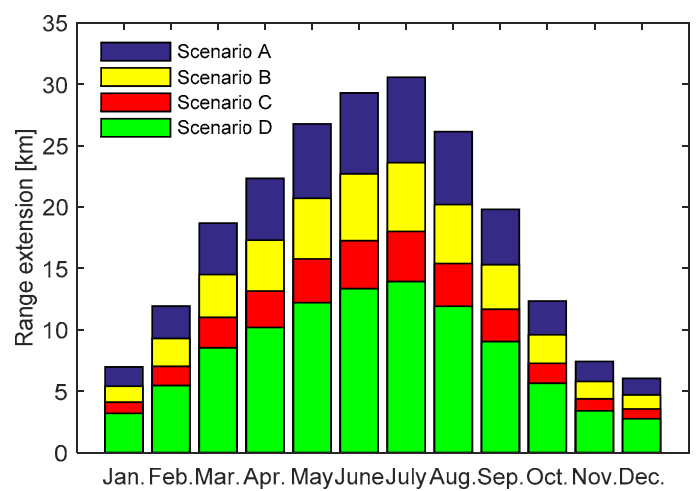

Figure 11: Estimated daily range extension values for the PLUS-MOBY vehicle demonstrator according to Scenarios A-D, considering the UDC and the average values of solar irradiance within each month.

\section{CONCLUSIONS}

The paper discussed the driving range extension benefits of the integration of a PV system into an electric vehicle. A simulation model was presented, including the PV panels, the DC/DC converter, the battery pack and the longitudinal vehicle dynamics. The PV system model was validated against experimental profiles of battery power and state-of-charge, for measured levels of solar irradiance. Simulations were run for different locations, seasons and mission profiles, to investigate the magnitude of the potential range extension. The results, excluding and including the power loss contributions caused by the ancillary systems, show that especially for the mission profiles typical of urban driving and at medium-high irradiance levels, the driving range can be significantly extended. The benefits for the specific vehicle prototype are enhanced by the introduction of an additional movable PV panel under the windshield. Further work will deal with the experimental validation of the presented range extension simulations.

\section{REFERENCES}

[1] Rizzo G., Automotive application of solar energy, IFAC Symposium on Advances in Automotive Control (AAC), 2010.

[2] Connors J., On the subject of solar vehicles and benefits of the technology, International Conference on Clean Electrical Power (ICCEP), 2007.

[3] Seal M.R., Viking 23 - zero emission in the city, range and performance on the freeway, EEE Northcon/94, 1994.

[4] Sasaki K., Yokota M., Nagayoshi H. and Kamisako K., Evaluation of electric motor and gasoline engine hybrid car using solar cells, Solar Energy Materials and Solar Cells, vol.47, nos. 1-4, pp. 259-263, 1997.

[5] Arsie I., Rizzo G., Sorrentino M., Optimal design and dynamic simulation of a hybrid solar vehicle, SAE Transactions - Journal of Engines, vol. 115, no. 3, pp. 805-811, 2007.

[6] Arsie I., Rizzo G., Sorrentino M., A model for optimal design of a hybrid solar vehicle, Review of Automotive Engineering, JSAE, vol. 29, no. 3, pp. 439-447, 2008.

[7] http://www.hybridcars.com/new-toyota-prius-plug-in-hybrid-gets-solarpanel-roof-but-not-in-u-s-yet, last accessed on 30/07/2016.

[8] Saitoh T., Hisada T., Gomi C., Maeda C., Improvement of urban air pollution via solar assisted super energy efficient vehicle, ASME JSES KSES International Solar Energy Conference, 1992.

[9] Coraggio G., Pisanti C., Rizzo G., Senatore A., A moving solar roof for a hybrid solar vehicle, IFAC Symposium on Advances in Automotive Control (AAC), 2010.

[10] http://www.moby-ev.eu/freemoby, last accessed on 01/04/2016.

[11] http://www.moby-ev.eu/plusmoby, last accessed on 01/04/2016.

[12] http://www.sunpowercorp.co.uk, last accessed on 01/04/2016.

[13] Yau H.T., Liang Q.C., Hsieh C.T., Maximum power point tracking and optimal Li-ion battery charging control for photovoltaic charging system, Advanced Technologies in Computer, Consumer and Control, vol.64, no. 5, pp.822-832, 2012.

[14] De Cesare G., Caputo D., Nascetti A., Maximum power point tracker for portable photovoltaic systems with resistive-like load, Solar Energy, vol. 80, no. 8, pp. 982-988, 2006.

[15] http://re.jrc.ec.europa.eu/pvgis/apps4/pvest.php, last accessed on $01 / 04 / 2016$

[16] Bellini A., Bifaretti S., Iacovone V., Cornaro C., Simplified model of a photovoltaic module, IEEE Applied Electronics Conference, 2009.

[17] Gao L., Liu S., Dougal R.A., Dynamic Lithium-Ion battery model for system simulation, IEEE Transactions on Components and Packaging Technologies, vol. 25, no. 3, pp. 495-505, 2002.

[18] De Pinto S., Camocardi P., Sorniotti A., Mantriota G., Perlo P., Viotto F., A four-wheel-drive fully electric vehicle layout with two-speed transmissions, IEEE Vehicle Power and Propulsion Conference (VPPC), 2014.

[19] De Pinto S., Sorniotti A., Gruber P., Camocardi P., Perlo P., Viotto F., Gearshift control with torque-fill for a 4-wheel-drive fully electric vehicle, IEEE Conference on Sustainable Mobility Applications, Renewables and Technology (SMART), 2015.

[20] Chatzikomis, C.I., Spentzas K.N., Mamalis A.G., Environmental and economic effects of widespread introduction of electric vehicles in Greece, European Transport Research Review, vol. 6, no. 4, pp. 365376, 2014.

[21] http://www.nissanusa.com/leaf-electric-car/, last accessed on $01 / 04 / 2016$.

[22] Patterson J., Alexander M., Gurr A., Preparing for a Life Cycle $\mathrm{CO}_{2}$ Measure. Ricardo plc, 2011.

[23] Technology roadmaps-electric and plug-in hybrid electric vehicles (EV/PHEV), International Energy Agency (IEA), 2011.

[24] https://ec.europa.eu/energy/sites/ener/files/documents/Electricity gas $\% 2$ Oretail\%20tables final.pdf, last accessed on 30/07/2016. 